\title{
Associations between farmer participation in veterinary herd health management programs and farm performance
}

\author{
M. Derks, ${ }^{\star 1}$ T. van Werven, ${ }^{*}$ H. Hogeveen, ${ }^{\star} \dagger$ and W. D. J. Kremer ${ }^{\star}$ \\ *Department of Farm Animal Health, Faculty of Veterinary Medicine, Utrecht University, Yalelaan 7, 3584 CL Utrecht, the Netherlands \\ †Business Economics Group, Wageningen University, Hollandseweg 1, 6706 KN Wageningen, the Netherlands
}

\begin{abstract}
In the past few decades, farms have increased in size and the focus of management has changed from curative to preventive. To help farmers cope with these changes, veterinarians offer veterinary herd health management (VHHM) programs, whose major objective is to support the farmer in reaching his farm performance goals. The association between farm performance and participation in VHHM, however, remains unknown. The aim of this paper was to compare farm performance parameters between participants and nonparticipants in VHHM and to differentiate within participation to evaluate the possible added value of VHHM on the farm. Five thousand farmers received a questionnaire about the level of VHHM on their farm. Farm performance parameters of these 5,000 farms were provided. For all respondents $(\mathrm{n}=1,013)$, farm performance was compared between participants and nonparticipants and within level of participation, using linear mixed and linear regression models. Farmers who participated in VHHM produced $336 \mathrm{~kg}$ of milk/cow per year more and their average milk somatic cell count (SCC) was 8,340 cells $/ \mathrm{mL}$ lower than farmers who did not participate in VHHM. Participating herds, however, had an older age at first calving $(+12 \mathrm{~d})$, a lower 56-d nonreturn rate percentage $(-3.34 \%)$, and a higher number of inseminations per cow (+0.09 inseminations). They also had more cows culled per year $(+1.05 \%)$, and a lower age at culling $(-70 \mathrm{~d})$. Participants in the most-extended form of VHHM (level 3) had a lower SCC $(-19,800$ cells $/ \mathrm{mL}$ ), fewer cows with high SCC $(-1.70 \%)$, fewer cows with new high SCC $(-0.47 \%)$, a shorter calving interval $(-6.01 \mathrm{~d})$, and fewer inseminations per heifer (-0.07 inseminations) than participants in the leastextended form of VHHM (level 1). Level 3 participants, however, also had more cows culled per year $(+1.74 \%)$ and a lower age at culling $(-103 \mathrm{~d})$. Discussing specific topics with the veterinarian (milk production, fertility,
\end{abstract}

Received March 8, 2013.

Accepted November 15, 2013.

${ }^{1}$ Corresponding author: m.derks@uu.nl and udder health) had only marginal effects on improving the farm performance parameters related to those topics. Given the relevance of fertility on the farm and the focus on longevity by society, it is important to determine underlying reasons for the negative associations of these topics with participation in VHHM. A longitudinal study could provide answers to this. For now, veterinarians should be aware of the associations. The increased milk production and milk quality could help the marketing of VHHM to farmers.

Key words: veterinary herd health management, dairy farmer, veterinarian, farm performance

\section{INTRODUCTION}

With regard to the herd size and management of dairy farms over the past few decades, some trends are apparent. Dairy farms have been coping with increased costs and have, therefore, needed to improve productivity. Apart from having more cows, cows have also been selected for higher levels of milk production (Noordhuizen and Wentink, 2001). This intensification led to more cows per farmer (and thus less individual attention) and more production-related problems (e.g., subfertility and subclinical disease; Shanks et al., 1978). The focus of dairy management has changed from curative to preventive (Cannas da Silva et al., 2006; LeBlanc et al., 2006). Individual sick cows have become an indicator for the herd, instead of a problem standing on its own. But even though modern dairy farmers are more aware of the costs of diseases on the farm and are willing to prevent disease, they do experience difficulties with the (early) detection of those disorders (Cannas da Silva et al., 2006). Monitoring and managing herd health has, therefore, become an important and challenging issue on the dairy farms.

Given their knowledge on epidemiology, farm management, and pathology in cows, veterinarians have always been an important sparring partner for dairy farmers regarding herd health. This started in the 1960s with mastitis control (Bramley and Dodd, 1984), followed by herd fertility schemes (Bramley and Dodd, 1984; Esslemont et al., 1985; Esslemont et al., 2001), 
disease prevention (De Kruif and Opsomer, 2004) and, finally, quality control programs ((Esslemont et al., 1985; Noordhuizen and Wentink, 2001; De Kruif and Opsomer, 2004) Nowadays, most veterinary practices offer veterinary herd health management (VHHM) to the farmer, during which they monitor herd health status and provide (preventive) advice (Derks et al., 2013). In the literature, VHHM is described as regularly scheduled farm visits, where data are recorded and analyzed and advice is provided. Veterinary herd health management follows a fixed structure of goal setting, advice, action, and evaluation (Brand et al., 1996). The major objective of VHHM should be to support the farmer in reaching his targets of farm performance (Noordhuizen, 2001; Noordhuizen and Wentink, 2001; De Kruif and Opsomer, 2004).

In practice, however, the execution of VHHM is more diverse. The goals of the farmer are not always clear to the veterinarian (Kristensen and Enevoldsen, 2008; Hall and Wapenaar, 2012). Also, not all farmers attend the full VHHM program; levels of participation can be determined. Some farmers only have their cows checked for pregnancy, whereas others discuss more topics with their veterinarian (Derks et al., 2013). Also, even though the literature states that VHHM is becoming more and more important (Noordhuizen, 2001; Noordhuizen and Wentink, 2001; De Kruif and Opsomer, 2004), few numbers are actually available in practice. Lievaart and Noordhuizen (1999) found a participation rate in the Netherlands of $37.2 \%$. Hall and Wapenaar (2012) found that in the United Kingdom, large differences existed between practices: $40 \%$ of the practices had less than $25 \%$ of their farmers enrolled in a VHHM program, whereas $30 \%$ of the practices had more than $50 \%$ of their farmers enrolled.

The difference in participation can perhaps be explained by the fact that the effects of participation in VHHM on farm performance and economics remain largely unclear. In the 1970s, a large Dutch field study showed that VHHM provided considerable financial benefits for the farmer (176 Dutch guilders per cow improvement in income feed cost margin), and that performance on fertility improved and the percentage of culled cows decreased significantly (Sol and Renkema, 1984). A follow-up study, however, published in the 1990 s, found that after the program was finished, the differences between participants and nonparticipants became nonexistent again after a few years (Hogeveen et al., 1992). Results of the benefits of VHHM at present remain scarce. Hässig et al. (2010) found that, on farms in Switzerland, only marginal differences existed in farm performance between farms participating in VHHM and farms not participating in VHHM. Given the fact that VHHM is becoming more and more im- portant for farmers and veterinarians, it is worthwhile knowing its (economic) benefits on the farm. Therefore, a need exists for more accurate numbers on the relationship between VHHM and farm performance, and on the relationship between the level of VHHM and farm performance. The aim of this paper was to compare farm performance parameters between participants and nonparticipants in VHHM and to differentiate within level of participation to evaluate the possible added value of VHHM on the farm.

\section{MATERIALS AND METHODS}

\section{Study Design}

In September 2011, 5,000 randomly selected dairy farmers with at least 40 milking cows, participating in monthly milk production registration (MPR) received a questionnaire per e-mail. The questionnaire was concerned with the participation in and execution of VHHM on the farm. Farm performance data from all 5,000 farmers was provided to the researchers by CRV BV (Arnhem, the Netherlands), a cooperative firm that, among other tasks, performs MPR for farmers. The results of the questionnaire were summarized, and farm performance was compared in 4 steps.

\section{Data Collection}

Questionnaire. The questionnaire (in supplementary materials, available online at http://dx.doi. org/10.3168/jds.2013-6781) was designed using the Tailored Design Method (Dillman, 2000) to improve understandability and response rate. Farmers were asked to indicate whether they participated in VHHM, and if they did, with what frequency. Next, they were asked which of 9 topics (fertility checks, advice on fertility, milk production, udder health, nutrition, young stock rearing, housing, claw health, and analysis of production numbers) were addressed during VHHM. Also, for each topic, farmers were asked to indicate with what frequency the topic was addressed (always, regularly, when problems arise, or never). Topics were chosen based on former research (Derks et al., 2011, 2012a,b). The questionnaire was introduced to farmers by an introduction letter through the mail; the questionnaire itself was sent $1 \mathrm{~d}$ later by e-mail.

Farm Data. All farmers selected for this study were participating in the MPR by CRV BV. The MPR is recorded every 4 to 6 wk. Participants receive information based on milk yield, SCC, and fertility parameters of individual cows and on a herd level. For this study, data on farm size (number of cows), fertility [calving interval (ClvI), age at first calving (AFC), heifer 
56-d nonreturn rate (\%), cow 56-d nonreturn rate (\%), number of inseminations/heifer, and number of inseminations/cow], udder health (mean SCC, percentage of cows with high SCC, and percentage of cows with new high SCC), milk production ( $\mathrm{kg}$ of milk/cow per year, fat percentage, and protein percentage), and herd longevity (percentage of cows culled per year and age at culling) were collected. High SCC was defined as $>250,000$ cells $/ \mathrm{mL}$ for cows and $>150,000$ cells $/ \mathrm{mL}$ for heifers. New high SCC was defined as the annual mean percentage of cows that exceeded this threshold per test date. Variables were chosen based on availability and importance during VHHM and were provided for all 5,000 farmers by CRV BV (Table 1). The data was collected at the same moment the questionnaire was sent, and comprised all milk recordings over the past $2 \mathrm{yr}$. The veterinary practices $(\mathrm{n}=270)$ that farmers were associated with were known for all farms.

\section{Data Analysis}

Farm performance variables were compared between groups in 4 steps: (1) between respondents and nonrespondents, (2) between participants and nonparticipants, (3) within level of participation, and (4) within different frequencies of discussion of topics.

Model Selection. Multiple options were available to compare the given data: (1) a Student's $t$-test/ANOVA, (2) a linear regression model correcting for herd size, and (3) a linear mixed model correcting for herd size (fixed variable) and associated veterinary practice (random variable). For each step, the most appropriate model was selected. Model 2 was chosen over model 1 if at least one of the significant outcomes per step was influenced by herd size. Model 3 was chosen over model 2 if the intraclass correlation coefficient (ICC) was higher than 0.10 for at least 1 of the significant outcomes per step. The ICC indicates how much of the total variance can be explained by differences between veterinary practices, and ranges from 0 to 1 . It is calculated by the following formula:

$$
\mathrm{ICC}=\frac{\sigma^{2}(p)}{\sigma^{2}(p)+\sigma^{2}(r e s)},
$$

where $\sigma^{2}$ is the variance, $p$ is the veterinary practice, and res is the residual.

Participants Versus Nonparticipants. Farm performance parameters of participants and nonparticipants were compared using a linear mixed model. Each available farm performance variable [ClvI, AFC, heifer 56-d nonreturn rate (\%), cow 56-d nonreturn rate $(\%)$, number of inseminations/heifer, number of

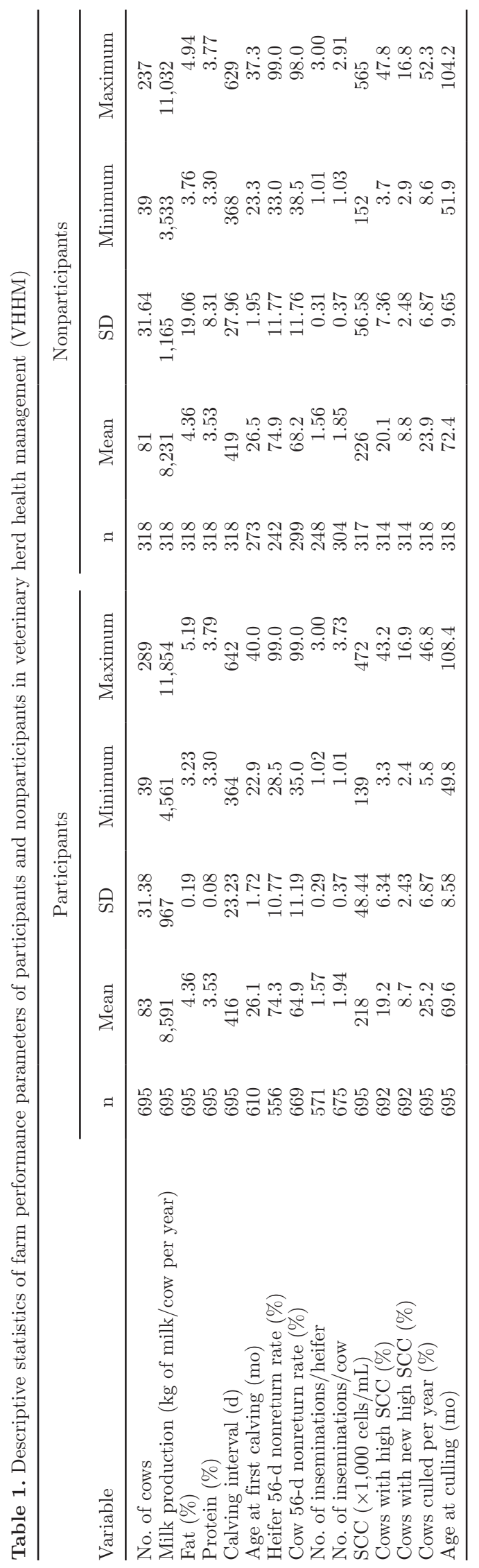


inseminations/cow, mean SCC, percentage of cows with high SCC, percentage of cows with new high SCC, $\mathrm{kg}$ of milk/cow per year, fat percentage, protein percentage, percentage of cows culled per year, and age at culling], except number of cows, was separately used in the model as a dependent variable, and number of cows and participation in VHHM (yes/no) as fixed, and veterinary practice as random independent variables. In total, because there were 14 outcome variables, the model was run 14 times. The $\beta$-estimates presented in the tables, therefore, directly relate to the relationship between VHHM and the presented variable. Number of cows was retained in the model if it was (1) significant or (2) had an influence of $>20 \%$ on the $\beta$-estimate. The final model could be described as follows:

$$
V A R_{i}=\mu+V Y N_{i}\left(+N o C_{i}\right),
$$

where $V A R$ is the dependent variable of interest, $\mu$ is the intercept, $V Y N$ is participation in VHHM (yes/no), $N o C$ is the number of cows, and $i$ corresponds to the $i$ th veterinary practice.

For all models, homoscedasticity, normality, and linearity were checked (where relevant) by visual inspection of the quantile-quantile plots of the standardized residuals, the plot of standardized residuals $\times$ the standardized predictor values, and the plot of standardized residuals $\times$ predictor variables. Residuals were checked on both farm and veterinary practice level. All models met the assumptions.

Respondents Versus Nonrespondents. The same approach as with the comparison between participants and nonparticipants was used for a nonresponse analysis. The same model was used, but the variable VHHM (yes/no) was replaced with response (yes/no; Appendix Tables A1 and A2). The final model can be described as follows:

$$
V A R_{i}=\mu+R Y N_{i}\left(+N o C_{i}\right),
$$

where $V A R$ is the dependent variable of interest, $\mu$ is the intercept, $R Y N$ is respondent (yes/no), NoC is the number of cows, and $i$ corresponds to the $i$ th veterinary practice.

Level of Participation and Farm Performance. Farmers participating in VHHM were divided into 3 levels of participation: level-1 participants had their veterinarian only check the cows for pregnancy, level-2 participants also discussed milk production, fertility, udder health, and (or) farm performance parameters, and level-3 participants discussed at least 1 of the topics of group 2 together with nutrition, young stock rearing, claw health, and (or) housing. The classification was based on previous findings from the same questionnaire that showed that farmers discussing nutrition, young stock rearing, claw health, and (or) housing with their veterinarian, also discussed milk production, fertility, udder health, and (or) farm performance parameters (Derks et al., 2013). The relationship between farm performance and level of participation in VHHM was determined with a linear mixed model. The model was built and fit statistics were checked in the same way as with the participants-versus-nonparticipants model. All models met the assumptions. The final model can be described as follows:

$$
V A R_{i}=\mu+\operatorname{LoP}_{i}\left(+N_{o} C_{i}\right),
$$

where $V A R$ is the dependent variable of interest, $\mu$ is the intercept, $L o P$ is the level of participation in VHHM, $N o C$ is the number of cows, and $i$ corresponds to the $i$ th veterinary practice.

Relationships Between Discussed Topics and Related Farm Performance Parameters. For 3 of the topics that could be discussed (fertility, milk production, and udder health) specific farm performance parameters were known. All farmers indicated the frequency with which these topics were discussed in the questionnaire (always, regularly, when problems arise, or never). The relationship between the frequency with which those topics were discussed and the specific farm performance parameters linked to these topics was checked using linear regression models. For each topic, the specific variables [milk production: milk production, fat (\%), and protein (\%); fertility: ClvI, AFC, heifer 56-d nonreturn rate (\%), cow 56-d nonreturn rate (\%), number of inseminations per heifer, and number of inseminations/cow; udder health: mean SCC, percentage of cows with high SCC, and percentage of cows with new high SCC) were used in the model as dependent variables; the number of cows and frequency of discussion were used as independent variables. Number of cows was retained in the model if it was (1) significant or (2) had an influence of $>20 \%$ on the $\beta$-estimate. The final model can be described as follows:

$$
V A R=\mu+F_{o D}(+N o C),
$$

where $V A R$ is the dependent variable of interest, $\mu$ is the intercept, $F_{O} D$ is the frequency with which the topic is discussed, and $N_{o} C$ is the number of cows.

For all models, homoscedasticity, normality, and linearity were checked (where relevant) by visual inspection of the quantile-quantile plots of the standardized residuals, the plot of standardized residuals $\times$ the standardized predictor values, the variance inflation factor and tolerance statistics, and the plot of standardized residuals $\times$ predictor variables. All models met the assumptions. 


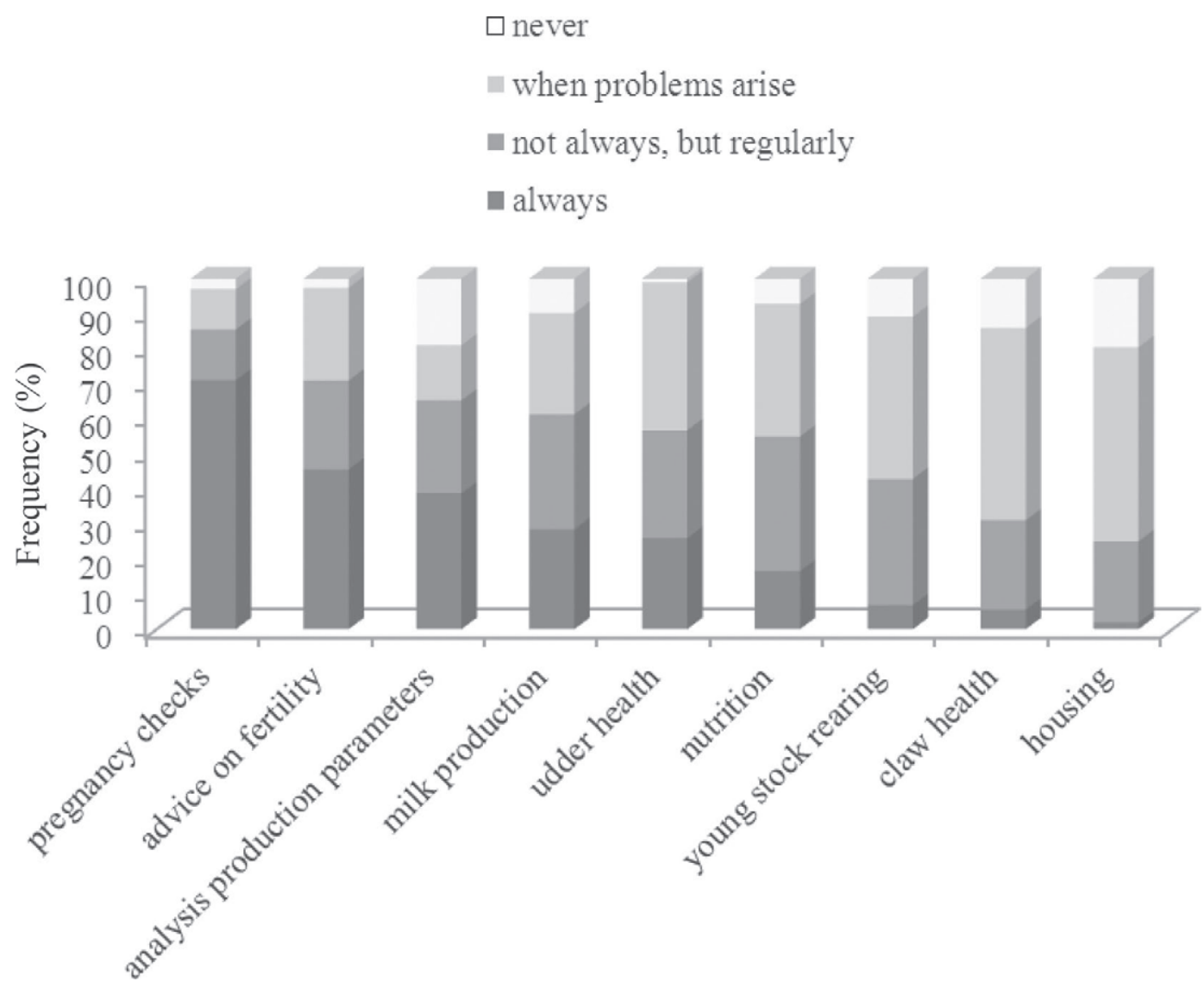

Figure 1. Overview of the frequency with which 9 veterinary herd health management (VHHM) topics were discussed during farm visits (n $=627)$.

\section{RESULTS}

\section{General Information on the Data Set}

Five thousand famers, associated with 270 veterinary practices, were approached to join the study, of which 1,013 returned the questionnaire (20\%). At least 1 farmer of all veterinary practices responded. No significant difference was observed in the response rate between practices. Of the respondents, 695 indicated they received some form of VHHM and 318 indicated they did not. Of the participants in VHHM, 272 participated in level 1, 275 in level 2, and 138 in level 3. Some topics were discussed more frequently than others (Figure 1).

\section{Comparison of Farm Performance Parameters Between Participants and Nonparticipants}

Descriptive statistics for all variables are provided in Table 1. Farmers who participated in VHHM produced $336 \mathrm{~kg}$ of milk/cow per year more and their average milk SCC was 8,340 cells/mL lower than farmers who did not participate in VHHM. Participants, however, had a higher AFC (+12 d), a lower 56-d nonreturn rate
$(-3.34 \%)$, and a higher number of inseminations per cow (+0.09 inseminations). They also had more cows culled per year $(+1.05 \%)$, and a lower age at culling $(-70 \mathrm{~d}$; Table 2$)$.

\section{Relationships Between the Level of Participation in VHHM and Farm Performance}

Compared with farmers in level 3, farmers in level 1 culled $1.74 \%$ cows less per year, had a longer ClvI $(+6.01 \mathrm{~d})$, a higher mean SCC $(+19,800$ cells $/ \mathrm{mL})$, a higher percentage of cows with high SCC $(+1.70 \%)$ and new high SCC $(+0.47 \%)$, and a higher age at culling $(+103 \mathrm{~d})$. For farmers in level 2 , the difference compared with the farmers in level 3 was a significantly higher age at culling $(+78 \mathrm{~d})$ and a higher percentage of cows culled per year $(+1.42 \%$; Table 3$)$.

\section{Relationships Between Discussed Topics and Related Farm Performance Parameters}

Only a few significant relationships between discussed topics and related farm performance parameters were 
Table 2. Outcomes of linear mixed models comparing farm performance parameters between participants and nonparticipants in veterinary herd health management $(\mathrm{VHHM})^{1}$

\begin{tabular}{|c|c|c|c|c|c|c|}
\hline \multirow[b]{2}{*}{ Variable } & \multicolumn{3}{|c|}{ Participant in VHHM (reference: yes) } & \multicolumn{3}{|c|}{ No. of cows } \\
\hline & $\beta$ & $\mathrm{SE}$ & $P$-value & $\beta$ & $\mathrm{SE}$ & $P$-value \\
\hline Cow 56 -d nonreturn rate $(\%)$ & 3.34 & 0.79 & $<0.01^{* *}$ & & & \\
\hline No. of inseminations/cow & -0.09 & 0.03 & $<0.01^{* *}$ & & & \\
\hline $\mathrm{SCC}(\times 1,000$ cells $/ \mathrm{mL})$ & 8.34 & 3.47 & $0.02 *$ & & & \\
\hline Age at culling (mo) & 2.28 & 0.59 & $<0.01^{* *}$ & -0.03 & 0.01 & $<0.01 * *$ \\
\hline No. of cows & -2.28 & 1.48 & 0.13 & & & \\
\hline Fat $(\%)$ & -0.46 & 1.25 & 0.71 & -4.03 & 4.66 & $0.02 *$ \\
\hline Protein (\%) & 0.76 & 0.54 & 0.16 & -1.84 & 0.72 & $0.01^{* *}$ \\
\hline Calving interval (d) & 1.34 & 1.64 & 0.41 & -0.04 & 0.02 & $0.05^{*}$ \\
\hline Heifer 56-d nonreturn rate (\%) & 0.63 & 0.84 & 0.46 & 3.53 & 1.35 & $<0.01^{* *}$ \\
\hline No. of inseminations/heifer & -0.01 & 0.02 & 0.54 & -0.01 & 0.01 & $<0.01^{* *}$ \\
\hline
\end{tabular}

${ }^{1}$ Number of cows was retained in the model when it was (1) significant or (2) had an influence of $>20 \%$ on the $\beta$-estimate (which directly relates to the relationship between VHHM and the presented variable). Veterinary practice was used as a random effect.

$* * P<0.01 ; * P<0.05$.

found in this study (Table 4). Farmers who discussed milk production at every VHHM visit had higher milk production than farmers who discussed milk production regularly, when problems arose, or never $(+238,+196$, and $+1,096 \mathrm{~kg} /$ cow per year, respectively). Farmers who discussed fertility at every VHHM visit had a significantly lower AFC of their heifers than farmers who never discussed fertility $(-41.3 \mathrm{~d})$. Farmers that discussed udder health only when problems arose had a significantly higher SCC than farmers who discussed udder health at every farm visit $(+11,500$ cells $/ \mathrm{mL})$.

\section{DISCUSSION}

This study aimed to compare farm performance parameters between participants and nonparticipants in VHHM and between different levels of participation to evaluate the possible added value of VHHM on the farm. Because the study design is cross-sectional, only relationships between VHHM and farm performance can be described, and no causalities. It could, therefore, be that the differences in participants and nonparticipants are caused by factors that were not in the scope of this study, such as farm management factors.

Of the 5,000 questionnaires that were sent to farmers, 1,013 were returned. The low response rate in comparison with other studies (Lievaart and Noordhuizen, 1999; Bergevoet et al., 2004) may have been caused by the fact that it was sent during the summer, which is indicated by farmers as a bad time to receive a questionnaire (Pennings et al., 2002), or by the fact that the questionnaire was sent by CRV BV, which sends farmers a lot of other information. The questionnaire might not have been opened. Given the low response rate, a risk of response bias exists. When the survey topic is appealing to possible respondents, they are more willing to fill out the questionnaire (Dillman, 2000; Huang et al., 2003). In this survey, farmers who were having VHHM might have had higher motivation to fill in the questionnaire than farmers without VHHM. An argument to support this may be found in Appendix Table A2, where the farm performance parameters are compared between respondents and nonrespondents. Respondents had a significantly higher milk yield, a shorter ClvI, and lower AFC, SCC, percentage of new SCC, and percentage of high SCC. Given the fact that the difference between the participants and nonparticipants in VHHM in our study had the same direction as the difference between the respondents and nonrespondents, it might very well be the case that the nonrespondents group contained a relatively large number of farms that were not participating in VHHM. However, as with all questionnaire studies, one has to be careful in generalizing results because of the potential bias.

Variables used in the analyses were chosen based on availability and importance during VHHM. Figure 1 provides an overview of the importance of discussed topics during VHHM. Fertility, milk production, and udder health were discussed most often. We added longevity of the herd, as it is a societal issue and we believe that it will become more important in the future. Data collection was, therefore, focused on these 4 topics. The most important parameters for those topics were selected and used for further analysis.

Data from the MPR was collected at the same time the questionnaire was sent and contained all recorded 


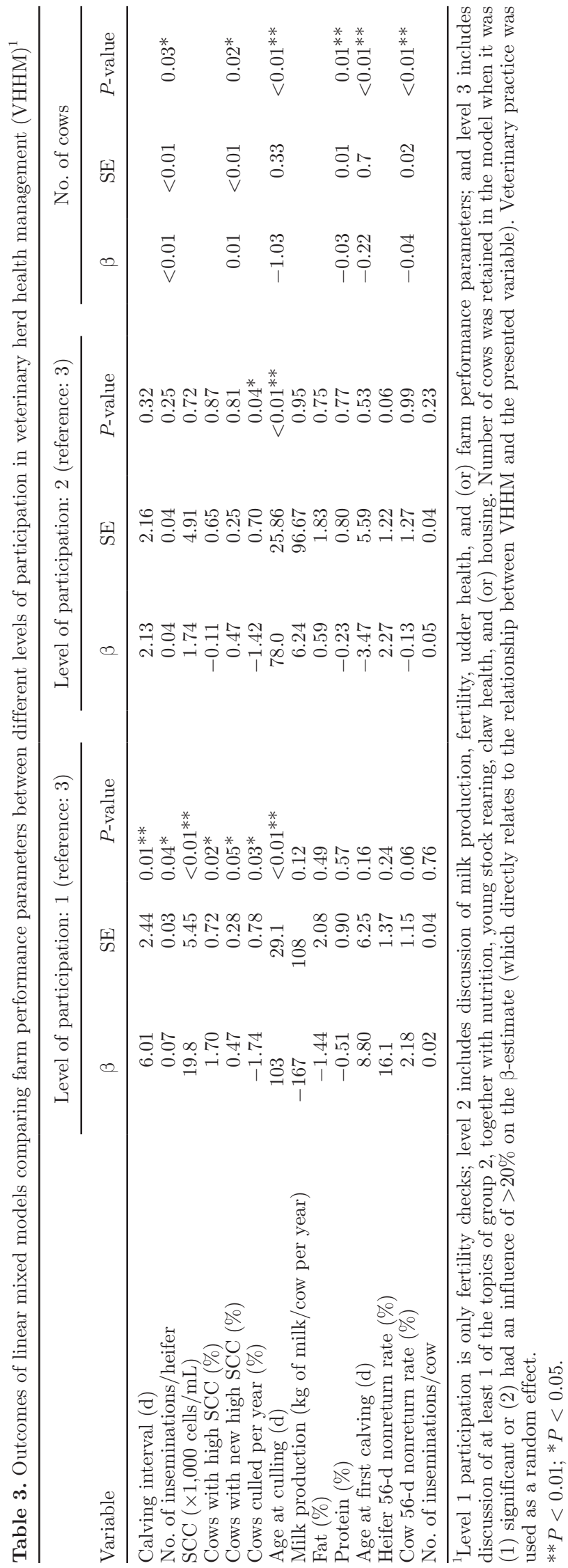

data from the past 2 yr. Some farmers may have started VHHM in those past $2 \mathrm{yr}$ and this may have influenced the results. As a check, the analysis was rerun for each separate year, to see whether the results would show any difference. No significant differences were found between samples from the first year and the second year, leading us to believe that the results were not heavily influenced by those farmers.

In this questionnaire, farmers were able to choose from 9 VHHM topics. Those topics were based on findings in previous research (Derks et al., 2011, 2012a). In theory, other topics than the ones named in this study could be discussed during VHHM. To prevent those topics being missed, the option "other" was added to the list of topics. No specific topic was named more than 6 times and, therefore, no topics were added to the analysis.

Data were analyzed using linear mixed models and linear regression models. This method was chosen over methods such as the Student's $t$-test or ANOVA for 2 reasons: first, the ability to correct for herd size: there were 27 significant outcomes of the models, of which 9 were also significantly affected by number of cows. Herd size, thus, is of influence in one-third of our significant outcomes. In short, because herd size is found to have an effect on farm performance, is regularly controlled for in other papers, and has an effect on one-third of the significant models in this paper, herd size is seen as an important variable to control for. Second, the models used allowed us to correct for veterinary practice. Implementation of VHHM differs between farmers, veterinarians, and veterinary practices. That makes it quite hard to compare between groups. In our study, we tried to overcome the differences between farmers, at least partially, by dividing them into levels of participation. We do not have information on the veterinarians, but we do have information on the associated veterinary practice. Veterinarian practices might have protocols for VHHM, or veterinarians might discuss their implementation of VHHM among colleagues. Also, larger veterinary practices might have more resources available (e.g., specialists). Therefore, veterinary practice could affect the farm performance. This influence was statistically checked using the following procedural analyses in different models to compare outcomes: a $t$-test, a linear model just correcting for herd size, and the final complete model as displayed in the paper.

Next, we used an ANOVA to see if any differences existed in means between farms clustered within practices. We took all farms clustered in one practice, calculated the mean for the practice, and compared means between practices. We did so with all practices and with practices $>10$ farms to ensure that strange or deviant means because of only 1 or 2 farms per practice 
Table 4. Outcomes of linear mixed models comparing farm performance parameters and frequency of discussion of linked veterinary herd health management (VHHM) topic ${ }^{1}$

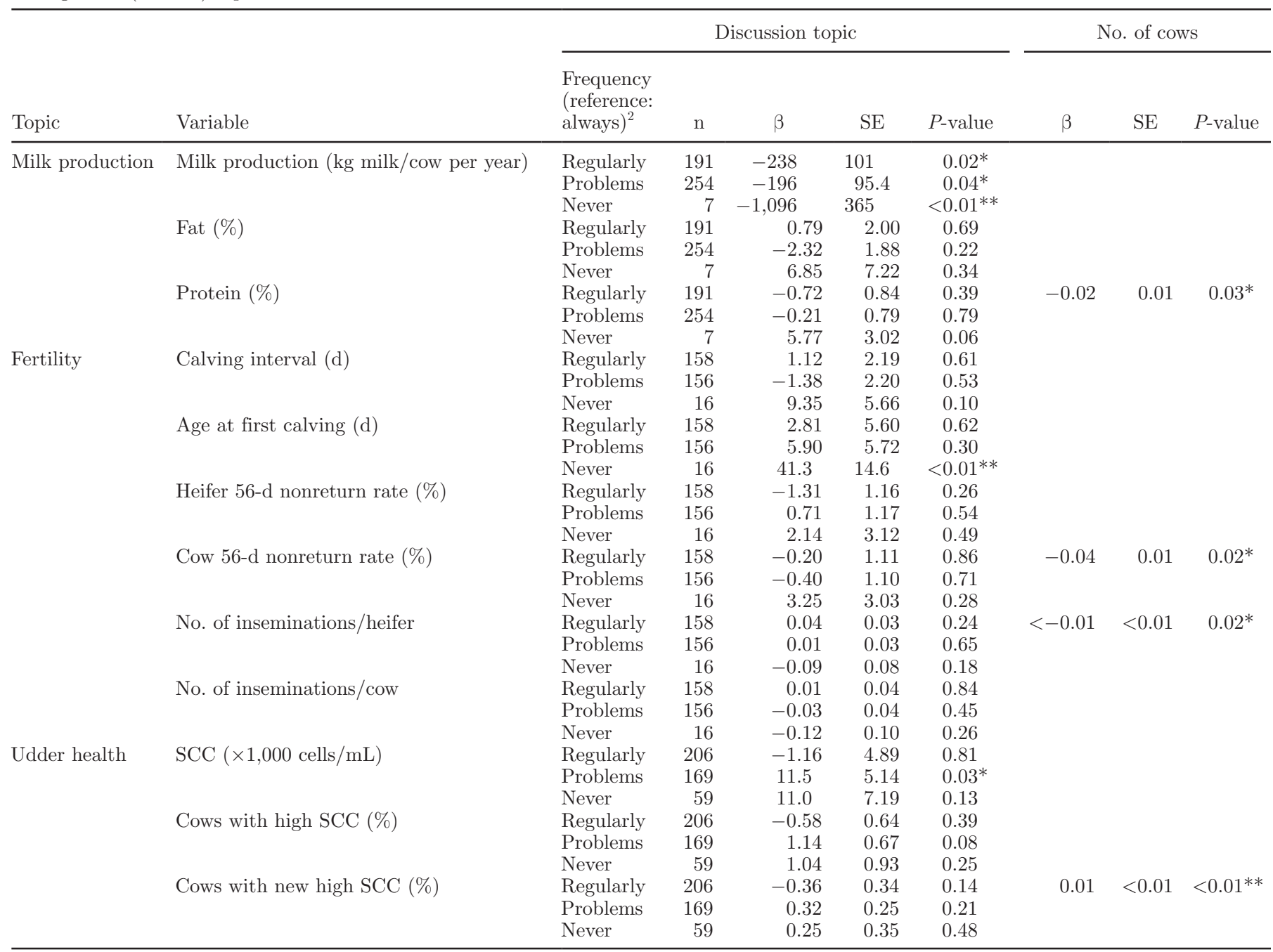

${ }^{1}$ Number of cows was retained in the model when it was (1) significant or (2) had an influence of $>20 \%$ on the $\beta$-estimate (which directly relates to the relationship between VHHM and the presented variable).

${ }^{2}$ Frequency of answer "always": milk production: $\mathrm{n}=161$; fertility: $\mathrm{n}=283$; udder health: $\mathrm{n}=179$. Problems $=$ topic was only discussed when problems arose.

${ }^{* *} P<0.01 ; * P<0.05$

were corrected for. In both calculations, all variables were statistically significant in the ANOVA.

Finally, we calculated the ICC for each of the linear mixed models used to compare participants and nonparticipants. The ICC was calculated by dividing the variance of the random effect by the sum of the variance of the added effect and the variance of the residuals.

Farmers who participated in VHHM had a higher milk production per cow per year $(+336 \mathrm{~kg})$, a higher number of inseminations per cow (+0.09 inseminations), a higher percentage of cows culled per year $(+1.05 \%)$, and a lower AFC $(-12 \mathrm{~d})$, a lower 56-d nonreturn rate for cows $(-3.34 \%)$, a lower mean SCC $(-8.340 \times 1,000$ cells $/ \mathrm{mL})$ and percentage high SCC $(-0.92 \%)$, and a lower age at culling $(-68.77 \mathrm{~d})$ than nonparticipants (Table 2). In terms of economics, the benefits outweigh the costs. The mean milk price in 2010 was $€ 0.326 /$ $\mathrm{kg}$ (LTO Noord, Zwolle, the Netherlands); heifer rearing costs were $€ 1,567 /$ heifer (Mohd Nor et al., 2012), which is $€ 1.96$ per day, given that the mean AFC for all respondents was $798.75 \mathrm{~d}$, insemination costs were $€ 20$ per insemination (Inchaisri et al., 2010), and culling costs were $€ 480 /$ cow (Huijps et al., 2008). We compare 2 imaginary farms of 80 cows, of which 1 participates and 1 does not. The mean culling rate for respondents is $24.78 \%$, which means that every year, 20 cows are replaced by heifers. The participating farm has $80 \times$ 
$336.59=26,927.2 \mathrm{~kg}$ of milk $/ \mathrm{yr}$ more, $20 \times 11.21=$ 224.2 fewer rearing days for their heifers, $80 \times 0.09=$ 7.2 more inseminations per year, and $80 \times 0.015=1.2$ more cows culled per year. In euros, this is $(26,927.2$ $\times 0.326)+(224.2 \times 1.96)-(7.2 \times 20)-(1.2 \times$ $480)=€ 8,497.63$. That is a gain of $€ 106.22 /$ cow per year. So, if the costs for VHHM do not exceed this amount, VHHM is beneficial for the farmer. However, no current numbers are available on the average costs per cow for participation in VHHM. In this calculation, we assume that the nonreturn rate (\%) is correlated with the total number of inseminations, and that the difference in SCC is mainly expressed in milk losses. Probably, there would be treatment costs involved with higher SCC (more clinical mastitis), but the number of clinical mastitis cases was not available in this data set. The results may, therefore, be even more positive for participants, as they have lower SCC and a lower percentage of cows with high SCC.

Overall milk production and milk quality appeared to be better in farms of VHHM participants. This is in line with previous research (Derks et al., 2013). Longevity and fertility of the herd appeared to be worse. Because VHHM focuses on prevention of disease and systematic approach of problems, it was expected that both fertility and longevity would be improved in participating farms. This would also have been in line with the research by Sol et al. (1984).

Fertility is perceived by farmers as the most important topic of VHHM (Derks et al., 2013). Farmers who experience problems with fertility might be more willing to join VHHM. The results for fertility may then be biased in a negative direction. Because this was a crosssectional study and disease status of the farm was not known, this cannot be checked. However, the frequency distributions of all fertility parameters were normally divided for both participants and nonparticipants, with no extreme outliers in the participants category. Therefore, there is no reason to assume that a few participants with big fertility problems heavily influenced the results. Another possibility is that fertility was worse on VHHM farms, as their milk production was higher; a negative correlation exists between milk yield and fertility (Berry et al., 2003). However, although significant, the differences in milk production were not extreme. A third explanation is that the nonparticipating farmers in the current study were biased in the more proactive direction. As stated before, farmers tend to fill out questionnaires that they are interested in. It is possible that especially those farmers that perform well without any veterinary advice responded. A fourth explanation is that the fertility advice that is given by veterinarians does not achieve its goal. Previous studies have shown that the communication between farmer and veterinar- ian is not always optimal (Jansen et al., 2010a; Sorge et al., 2010; Derks et al., 2012b). Future studies on the relationship between level of compliance and farm performance parameters are, therefore, recommended to determine whether not quantity, but quality of advice is the better predictor of farm performance.

With regard to culling rate, veterinarians might have advised farmers to get rid of their sick or problematic cows; they might have advised culling where farmers would have otherwise waited. However, this is not in line with the findings of Sol et al. (1984), who found that participation in VHHM had a positive effect on culling rates. In future studies, it would be interesting to incorporate the reasons for culling. Those reasons were not known here.

Farmers in participation level 3 had a higher percentage cows culled per year, shorter ClvI, and lower mean SCC, percentage of cows with high SCC and new high SCC, and age at culling than farmers in participation level 1. Therefore, it seems that farmers who participate in an extended form of VHHM have better farm performance parameters for fertility and udder health, but perform less in terms of longevity of the herd. These results may be explained by intrinsic motivation of farmers: a study in Denmark showed that farmers who participate in a more extended version of herd health service are more compliant with veterinary advice (Lind, 2012). The previous argument, about the veterinarian advising to cull cows may also be valid for culling rate.

Only few relationships between frequency of discussion of a specific topic and related farm performance parameters were found. This was unexpected, as specific advice on these topics is expected to have a positive influence on farm performance parameters related to that topic. It might be possible that the farmers who discussed this topic with their veterinarian always or regularly have had problems in the past. Given the cross-sectional nature of the study and the lack of animal health data, this cannot be ruled out. Also here, the quality of the given advice was not taken into account. Perhaps quality of advice is more important than quantity. For milk production an increasing frequency of discussion led to a higher milk yield. This is in line with the results of Hogeveen et al. (1992). Another interesting thought is the codependence between the need for advice and the performance on a specific topic. In the current study, farm performance variables were chosen to be an outcome variable because farm performance is believed to be dependent on the amount of advice received on that particular topic. However, the amount of advice received may also be dependent on the farm performance in that particular field. It is very well possible that the need for advice increases 
as problems in that area increase. In that case, the analysis should be reversed. However, it is not possible to determine the direction of this relationship from our data set and, therefore, the original approach was kept.

This study focused on the relationship between VHHM and farm performance. It is, however, important to remember that the success of VHHM is, at least partly, dependent on the relationship and cooperation between farmer and veterinarian. Previous research has shown that the relationship farmers have with their veterinarian is a significant predictor for participation in VHHM (Derks et al., 2013). Also, veterinarians are not always aware of the goals the farmer wants to reach (Kristensen and Enevoldsen, 2008; Derks et al., 2012b; Hall and Wapenaar, 2012), although knowledge of the farmer's goals is important for compliance to veterinary advice (Sorge et al., 2010). Finally, farmers can be hard to reach with preventive advice and sometimes need a more tailor-made approach (Jansen et al., 2010b). Given the unique relationship between farmer and veterinarian, within our data set, there will have been both matches and mismatches. This will have influenced the results of our study.

The results of this study show that a positive relationship exists between farm performance parameters and (level of participation in) VHHM. It would be interesting to look into longitudinal data to find out whether this is a causal relationship. For now, veterinarians can use the results of this study to market VHHM to farmers. Especially those farmers who prefer only pregnancy checks may be persuaded to expand VHHM with the current findings. Veterinarians might also consider, in light of the public discussion on animal welfare and longevity, reviewing their culling strategy together with the farmer.

\section{CONCLUSIONS}

Farmers who participated in VHHM had a higher milk production per cow per year and a lower mean SCC than farmers who did not participate in VHHM. They, however, performed worse on fertility and longevity of the herd. Within the population of participating farmers, extension of the number of VHHM topics discussed led to better performance on udder health and fertility, but again worse performance on longevity. Discussing specific topics did not seem directly related to the improvement of farm performance parameters related to those topics. Future research should focus on longitudinal data to find causal relationships on the relationship between quality of advice and farm performance parameters and on the (more detailed) financial benefits of VHHM for the farmer.

\section{ACKNOWLEDGMENTS}

The authors acknowledge all farmers participating in the study. Also, we thank Hans Vernooij (Faculty of Veterinary Medicine, Department of Farm Animal Health, Utrecht University, Utrecht, the Netherlands) for his great input for the statistical analyses. Last, but not least, we thank CRV BV (Arnhem, the Netherlands) for providing the data and for funding this study.

\section{REFERENCES}

Bergevoet, R. H. M., C. J. M. Ondersteijn, H. W. Saatkamp, C. M. J. Van Woerkum, and R. B. M. Huirne. 2004. Entrepreneurial behaviour of Dutch dairy farmers under a milk quota system: Goals, objectives and attitudes. Agric. Syst. 80:1-21.

Berry, D. P., F. Buckley, P. Dillon, R. D. Evans, M. Rath, and R. F. Veerkamp. 2003. Genetic relationships among body condition score, body weight, milk yield, and fertility in dairy cows. J. Dairy Sci. 86:2193-2204.

Bramley, A. J., and F. H. Dodd. 1984. Reviews of the progress of dairy science: Mastitis control-Progress and prospects. J. Dairy Res. 51:481-512.

Brand, A., J. P. T. M. Noordhuizen, and Y. H. Schukken, ed. 1996. Herd Health and Production Management in Dairy Practice. Wageningen Pers, Wageningen, the Netherlands.

Cannas da Silva, J., J. P. T. M. Noordhuizen, M. Vagneur, R. Bexiga, C. C. Gelfert, and W. Baumgartner. 2006. Veterinary dairy herd health management in Europe constraints and perspectives. Vet. Q. 28:23-32.

De Kruif, A., and G. Opsomer. 2004. Integrated dairy herd health management as the basis for prevention. Vlaam. Diergeneeskd. Tijdschr. 73:44-52.

Derks, M., L. M. A. van de Ven, T. van Werven, W. D. J. Kremer and H. Hogeveen. 2012a. The perception of veterinary herd health management by Dutch dairy farmers and its current status in the Netherlands: A survey. Prev. Vet. Med. 104:207-215.

Derks, M. T. Van Werven, H. Hogeveen, and W. D. J. Kremer. 2012b. Straightening out priorities: How aware is the veterinarian of farmers' wishes and goals regarding veterinary herd health management? Abstract OC:221:23 in Abstract Book XXVII World Buiatrics Congress 2012. Associação Portuguesa de Buiatria, Lisbon, Portugal.

Derks, M., T. van Werven, W. D. J. Kremer, and H. Hogeveen. 2011. Veterinary on-farm counselling on dairy farms: The veterinarians' vision. Pages 179-185 in Udder Health and Communication. Wageningen Academic Publishers, Wageningen, the Netherlands.

Derks, M., T. van Werven, H. Hogeveen, and W. D. J. Kremer. 2013. Veterinary herd health management programs on dairy farms in the Netherlands: Use, execution, and relations to farmer characteristics. J. Dairy Sci. 96:1623-1637.

Dillman, D. A. 2000. Mail and Internet Surveys: The Tailored Design Method. John Wiley \& Sons, New York, NY.

Esslemont, R. J., J. H. Bailie, and M. J. Cooper. 1985. Fertility Management in Dairy Cattle. Collins Professional and Technical Books, London, UK.

Esslemont, R. J., M. A. Kossaibati, and J. Allcock. 2001. Economics of fertility in dairy cows. Br. Soc. Anim. Sci. Occ. Publ. 26:19-29.

Hall, J., and W. Wapenaar. 2012. Opinions and practices of veterinarians and dairy farmers towards herd health management in the UK. Vet. Rec. 170:441.

Hässig, M., D. Kemper-Gisler, A. Liesegang, and U. Braun. 2010. Vergleich von Leistungsfähigkeit und tierärztlichen Kosten in landwirtschaftlichen Betrieben mit und ohne Integrierte Tierärztliche Bestandesbetreuung (ITB). Schweiz. Arch. Tierheilk. 152:470 476. 
Hogeveen, H., A. A. Dykhuizen, and J. Sol. 1992. Short- and long-term effects of a 2 year dairy herd health and management program. Prev. Vet. Med. 13:53-58.

Huang, J. Y., S. M. Hubbard, and K. P. Mulvey. 2003. Obtaining valid response rates: Considerations beyond the tailored design method. Eval. Program Plann. 26:91-97.

Huijps, K., T. J. G. M. Lam, and H. Hogeveen. 2008. Costs of mastitis: Facts and perception. J. Dairy Res. 75:113-120.

Inchaisri, C., R. Jorritsma, P. L. A. M. Vos, G. C. van der Weijden, and H. Hogeveen. 2010. Economic consequences of reproductive performance in dairy cattle. Theriogenology 74:835-846.

Jansen, J., R. J. Renes, H. Klinkert, and T. J. G. M. Lam. 2010a. Improving udder health management: Veterinarians' perceptions and communication skills. Wageningen University, Wageningen, the Netherlands.

Jansen, J., C. D. M. Steuten, R. J. Renes, N. Aarts, and T. J. G. M. Lam. 2010b. Debunking the myth of the hard-to-reach farmer: Effective communication on udder health. J. Dairy Sci. 93:12961306.

Kristensen, E., and C. Enevoldsen. 2008. A mixed methods inquiry: How dairy farmers perceive the value(s) of their involvement in an intensive dairy herd health management program. Acta Vet. Scand. 50:50

LeBlanc, S. J., K. D. Lissemore, D. F. Kelton, T. F. Duffield, and K. E. Leslie. 2006. Major advances in disease prevention in dairy cattle. J. Dairy Sci. 89:1267-1279.

Lievaart, J. J., and J. P. T. M. Noordhuizen. 1999. Veterinary assistance to dairy farms in the Netherlands: An assessment of the situation by dairy farmers. Tijdschr. Diergeneeskd. 124:734-740.
Lind, A. K. 2012. The association between farmers' participation in herd health programmes and their behaviour concerning treatment of mild clinical mastitis. Acta Vet. Scand. 54:62.

Mohd Nor, N., W. Steeneveld, M. C. Mourits, and H. Hogeveen. 2012. Estimating the costs of rearing young dairy cattle in the Netherlands using a simulation model that accounts for uncertainty related to diseases. Prev. Vet. Med. 106:214-224.

Noordhuizen, J. P. T. M. 2001. Changes in the veterinary management of dairy cattle: Threats or opportunities? Vet. Sci. Tomorrow April 2001:1-10.

Noordhuizen, J. P. T. M., and G. H. Wentink. 2001. Developments in veterinary herd health programmes on dairy farms: A review. Vet. Q. 23:162-169.

Pennings, J. M. E., S. H. Irwin, and D. L. Good. 2002. Surveying farmers: A case study. Rev. Agric. Econ. 24:266-277.

Shanks, R. D., A. E. Freeman, P. J. Berger, and D. H. Kelley. 1978. Effect of selection for milk production and general health of the dairy cow. J. Dairy Sci. 61:1765-1772.

Sol, J., and J. A. Renkema. 1984. A three year herd health and management program on thirty Dutch dairy farms. I. objectives, methods and main results. Vet. Q. 6:141-148.

Sol, J., J. Stelwagen, and A. A. Dijkhuizen. 1984. A three year herd health and management program on thirty Dutch dairy farms. II. Culling strategy and losses caused by forced replacement of dairy cows. Vet. Q. 6:149-157.

Sorge, U., D. Kelton, K. Lissemore, A. Godkin, S. Hendrick, and S. Wells. 2010. Attitudes of Canadian dairy farmers toward a voluntary Johne's disease control program. J. Dairy Sci. 93:1491-1499. 


\section{APPENDIX}

Table A1. Descriptive statistics of farm performance parameters of respondents and nonrespondents to the questionnaire

\begin{tabular}{|c|c|c|c|c|c|c|c|c|c|c|}
\hline \multirow[b]{2}{*}{ Variable } & \multicolumn{5}{|c|}{ Nonrespondents } & \multicolumn{5}{|c|}{ Respondents } \\
\hline & $\mathrm{n}$ & Mean & $\mathrm{SD}$ & Minimum & Maximum & $\mathrm{n}$ & Mean & SD & Minimum & Maximum \\
\hline No. of cows & 3,986 & 86 & 38.21 & 34 & 464 & 1,013 & 83 & 31.46 & 39 & 289 \\
\hline Milk production ( $\mathrm{kg}$ of milk/cow per year) & 3,986 & 8,401 & 1,031 & 4,108 & 12,768 & 1,013 & 8,478 & 1,046 & 3,533 & 11,854 \\
\hline Fat $(\%)$ & 3,986 & 4.37 & 0.20 & 3.45 & 6.12 & 1,012 & 4.36 & 0.19 & 3.23 & 5.19 \\
\hline Protein (\%) & 3,986 & 3.53 & 0.09 & 3.26 & 4.26 & 1,012 & 3.53 & 0.08 & 3.30 & 3.79 \\
\hline Calving interval (d) & 3,986 & 421 & 25.26 & 349 & 628 & 1,013 & 417 & 24.82 & 364 & 642 \\
\hline Age at first calving (mo) & 3,392 & 26.5 & 2.02 & 22.2 & 44.2 & 883 & 26.3 & 1.80 & 22.9 & 40.0 \\
\hline Heifer 56 -d nonreturn rate (\%) & 2,977 & 75.2 & 11.43 & 16.50 & 99.00 & 798 & 74.5 & 11.01 & 28.50 & 99.00 \\
\hline Cow 56 -d nonreturn rate $(\%)$ & 3,755 & 66.8 & 11.64 & 27.50 & 99.50 & 968 & 65.9 & 11.46 & 35.00 & 99.00 \\
\hline No. of inseminations/heifer & 3,084 & 1.56 & 0.31 & 1.01 & 4.15 & 819 & 1.57 & 0.30 & 1.01 & 3.00 \\
\hline No. of inseminations/cow & 3,802 & 1.89 & 0.37 & 1.01 & 3.87 & 979 & 1.91 & 0.37 & 1.01 & 3.73 \\
\hline $\mathrm{SCC}(× 1,000$ cells/mL $)$ & 3,984 & 228 & 58.21 & 129.9 & 744.9 & 1,012 & 220 & 51.26 & 138.9 & 565.1 \\
\hline Cows with high SCC (\%) & 3,967 & 20.3 & 7.21 & 0.3 & 57.0 & 1,006 & 19.5 & 6.68 & 3.3 & 47.8 \\
\hline Cows with new high SCC (\%) & 3,967 & 9.0 & 2.56 & 0.3 & 20.2 & 1,006 & 8.7 & 2.49 & 2.4 & 16.9 \\
\hline Cows culled per year (\%) & 3,986 & 25.2 & 7.15 & 3.9 & 79.4 & 1,013 & 24.8 & 6.89 & 5.8 & 52.3 \\
\hline Age at culling (mo) & 3,986 & 70.4 & 8.81 & 25.4 & 122.1 & 1,013 & 70.5 & 9.02 & 49.8 & 108.4 \\
\hline
\end{tabular}

Table A2. Outcomes of linear mixed models comparing farm performance parameters between respondents and nonrespondents to the questionnaire ${ }^{1}$

\begin{tabular}{|c|c|c|c|c|c|c|}
\hline \multirow[b]{2}{*}{ Variable } & \multicolumn{3}{|c|}{ Respondent (reference: yes) } & \multicolumn{3}{|c|}{ No. of cows } \\
\hline & $\beta$ & $\mathrm{SE}$ & $P$-value & $\beta$ & $\mathrm{SE}$ & $P$-value \\
\hline Milk production (kg of milk/cow per year) & -84.0 & 35.7 & $0.02^{*}$ & 2.02 & 0.40 & $<0.01^{* *}$ \\
\hline Fat $(\%)$ & 0.94 & 0.66 & 0.16 & & & \\
\hline Protein $(\%)$ & -0.04 & 0.30 & 0.99 & -0.02 & 0.01 & $<0.01^{* *}$ \\
\hline Calving interval (d) & 3.49 & 0.85 & $<0.01 * *$ & -0.04 & 0.01 & $<0.01^{* *}$ \\
\hline Age at first calving (mo) & 0.24 & 0.10 & $<0.01^{* *}$ & -0.22 & 0.03 & $<0.01^{* *}$ \\
\hline Heifer 56-d nonreturn rate (\%) & 0.71 & 0.45 & 0.11 & 0.03 & $<0.01$ & $<0.01^{* *}$ \\
\hline Cow 56 -d nonreturn rate $(\%)$ & 0.90 & 0.41 & $0.03^{*}$ & 0.02 & $<0.01$ & $<0.01 * *$ \\
\hline No. of inseminations/heifer & -0.01 & 0.01 & 0.30 & -0.01 & $<0.01$ & $<0.01^{*} *$ \\
\hline No. of inseminations/cow & -0.02 & 0.01 & 0.08 & $<0.01$ & $<0.01$ & $0.01^{* *}$ \\
\hline $\mathrm{SCC}(\times 1.000$ cells $/ \mathrm{mL})$ & 7.58 & 7.98 & $<0.01 * *$ & & & \\
\hline Cows with high SCC (\%) & 0.83 & 0.25 & $<0.01^{* *}$ & & & \\
\hline Cows with new high SCC (\%) & 0.29 & 0.09 & $<0.01^{* *}$ & 0.01 & $<0.01$ & $<0.01^{* *}$ \\
\hline Cows culled per year (\%) & 0.28 & 0.24 & 0.23 & 0.01 & $<0.01$ & $0.02 *$ \\
\hline Age at culling (mo) & 0.10 & 0.29 & 0.72 & -0.80 & 0.10 & $<0.01^{* *}$ \\
\hline
\end{tabular}

${ }^{1}$ Number of cows was retained in the model when it was (1) significant or (2) had an influence of $>20 \%$ on the $\beta$-estimate (which directly relates to the relationship between veto erinary herd health management and the presented variable). Veterinary practice was used as a random effect.

$\omega \quad * * P<0.01 ; * P<0.05$. 